Assessing the impact of the funding environment on researchers' risk aversion: the use of citation statistics

Journal Article

Author(s):

Zoller, Frank A.; Zimmerling, Eric; Boutellier, Roman (D)

Publication date:

2014-09

Permanent link:

https://doi.org/10.3929/ethz-b-000080285

Rights / license:

In Copyright - Non-Commercial Use Permitted

Originally published in:

Higher Education 68(3), https://doi.org/10.1007/s10734-014-9714-4 


\title{
Assessing the impact of the funding environment on researchers' risk aversion: the use of citation statistics
}

\author{
Frank A. Zoller • Eric Zimmerling • Roman Boutellier
}

Published online: 19 January 2014

(C) Springer Science+Business Media Dordrecht 2014

\begin{abstract}
The funding environment has a profound impact on researchers' behavior. In particular, it influences their freedom and readiness to conduct research ventures with highly uncertain outcomes. In this conceptual paper, we propose a concise new methodology to evaluate researchers' risk aversion based on citation statistics. The derived singlenumber criterion $P_{R}$ is sensitive to the ratio of high impact versus average impact work, based on citation counts. We demonstrate the usefulness of $P_{R}$ on a micro and meso level in the field of chemistry. $\mathrm{P}_{\mathrm{R}}$ is a potentially valuable tool for managers in higher education, to control for the impact of their funding instruments. The conducted testing may, in addition, contribute to the literature stream dealing with the effects of peer review in the allocation of research funding. Our results support the view that peer review fosters mainstream research. However, faculties with the highest percentages of third-party funding may find ways to avoid the restrictive effects. We also find evidence that permanent positions back risky research endeavors.
\end{abstract}

Keywords Allocation $\cdot \mathrm{P}_{\mathrm{R}} \cdot$ Risk-taking $\cdot$ Risk-return pattern $\cdot$ Third-party funding · Peer review

Electronic supplementary material The online version of this article (doi:10.1007/s10734-014-9714-4) contains supplementary material, which is available to authorized users.

F. A. Zoller · E. Zimmerling $\cdot$ R. Boutellier $(\bowtie)$

Technology and Innovation Management, HG F 45, Swiss Federal Institute of Technology

Zurich (ETH Zurich), Rämistrasse 101, CH-8092 Zurich, Switzerland

e-mail: roman.boutellier@sl.ethz.ch

F. A. Zoller

e-mail: fzoller@ethz.ch

E. Zimmerling

TUM School of Management, Strategy and Organization, Technische Universität München, Arcisstraße 21, D-80333 Munich, Germany 


\section{Introduction}

Faculties adapt their research behavior to the funding environment to which they are exposed. This adaptation presumably impacts research agendas and, therefore, the research output. Scholars have studied the impact of various input variables on the research output of a wide range of research entities. This paper intends to broaden the toolset for studying the impact of different funding mechanisms on research output. We derive researchers' readiness to assume risks from the citation characteristics of their published output. We believe that it is relevant for policymakers and managers in higher education to understand how differences in the funding environment influence researchers' risk aversion, since, for example, breakthrough research is associated with risk-taking. To the authors' knowledge, this paper presents the first single-number criterion to evaluate the impact of funding instruments on researcher's risk-taking comprehensively, and to illustrate risk-return patterns. The criterion is derived in the first part of the paper, which reviews the literature. Furthermore, we evaluate the new tool, using examples at an individual (micro), and an institutional (meso) level of analysis. In the last part, we discuss policy related implications.

\section{Funding environment}

With easy access to the Web of Science ${ }^{1}$ and similar databases, the use of bibliometrics to analyze research output quantitatively has become increasingly popular. The output or productivity of researchers has been assessed by counting patents and publications, or their respective number of citations. Input factors, such as the age of the researchers (e.g. Bonaccorsi and Daraio 2003), faculty structure (e.g. Dundar and Lewis 1998), and especially group size (e.g. Carayol and Matt 2006; Leitner et al. 2007) have been analyzed, with respect to scientific output. However, among the different input factors, funding is regarded as having the highest impact (Auranen and Nieminen 2010), and has, accordingly, often been subject of corresponding studies (e.g. Butler 2003; Leydesdorff and Wagner 2009a; Lewison and Dawson 1998).

Scholars' aim to better understand the determinants of research productivity goes along with the pressure for more accountability in public research spending. The call for an efficient expenditure of public finances has increased significantly, including in the context of publicly funded research (Weber and Duderstadt 2004). For this reason, a shift from recurrent and stable core funding to performance-based allocation has taken place, especially in Europe (Lepori et al. 2007). Funding channels have been changed from distributive or proportional allocation towards a more contractually oriented approach (Geuna 2001). Market-like instruments have emerged. Decentralized agencies allocate funds following an application and evaluation process which is often described as having a negative correlation with intellectual pluralism, and a positive correlation with reputational competition (Whitley 2003). Third-party funding is believed to have a discipline effect and is, therefore, seen as increasing the quantitative research output (Bolli and Somogyi 2011). However, the findings of the impact on research quality are mixed. ${ }^{2}$ In the course of reforms in several higher education systems, the ratio between non-permanent staff and tenured faculty

\footnotetext{
1 Thomson Reuters, http://thomsonreuters.com/products_services/science/science_products/a-z/web_of_ science/.

${ }^{2}$ Hornbostel (2001) or Lewison and Dawson (1998), e.g., found a positive impact, while Leydesdorff and Wagner (2009b) found positive and negative influence. Butler (2003) found indications of a negative impact. Zhao (2010) or Carayol and Matt (2004) found no influence.
} 
members has increased, and tenure track positions have been fostered (Musselin 2005). A promotion or a renewal of a labor contract is-similar to the allocation of third-party funding-usually associated with an assessment based on a peer review process. In such a peer review process, the focus is either put on the applicant's track record or, in the case of project funding, mostly on the proposed research agenda, including the expected results. The applicant in the latter case will, therefore, only receive funding on the condition of following their research agenda, which had been presented to the reviewing peer group.

\section{Risk-taking and research output}

Policy makers can influence the research landscape by changing the funding environment. Researchers will adapt to the changes in the environment, and react to funding agencies' actual allocation criteria (Liefner 2003), and adaptation has even become a key success factor (Tammi 2009; Laudel 2006a). In the case of evaluation-based funding, the adaption process is biased towards short-term performance, and conventional or mainstream approaches, leading to a neglect of long-term or risky research (Marginson and Considine 2000, p. 171). Peer judgment considerably reduces the probability of receiving funds for "exotic" research projects. Also outstanding, risky projects were rarely supported (Laudel 2006a; Weingart 2005; Henkel 2000, p. 118). But, breakthrough research-in the sense of Thomas Kuhn (1962) - is often of a speculative and unorthodox nature. Therefore, it does often not receive favorable peer judgments. Even Nobel Prize awarded research failed initially to receive peer judged project funding (Tatsioni et al. 2010). Risk aversion can, therefore, be seen as promoting more mainstream and less ground-breaking research (Heinze 2008). Ground-breaking research requires the freedom and flexibility to seize opportunities, thus abandoning initial research plans (Bovier et al. 2001). Taking high risks is thus associated with a few ground-breaking discoveries of high impact, and a very large number of failures which, at best, lead to low-impact output. Mainstream research is often problem-solving, and reflected in output of moderate impact. In its entirety, however, mainstream research is of high significance for scientific progress.

\section{Assessing risk-return patterns}

The number of citations is a good indicator of research impact (Goldfarb 2008). Faculties that conduct risky research projects have a high probability of ending up at a dead end, or find themselves adjusting the research direction after a certain period of time. Those attempts most likely receive little to no attention in the form of citations. If, however, the rare case sets in, and a risky research venture is successful, the results and findings are often revolutionary and fundamentally new. As a result, they gain the highest possible level of attention and are frequently cited (Liefner 2003). Mainstream research often moderately expands the state of knowledge in well-known areas of study. Researchers and sponsors risk little: relatively easily publishable results with an average number of citations, is the most likely outcome. Researchers often strike a balance between high risk and mainstream research by addressing various research projects of different risk levels.

Measure for risk-return pattern

By plotting the rank abundance curves of citation counts, similar to Hirsch's well known $h$ index (Hirsch 2005), we can expect to be able to, based on the preceding discussion, 


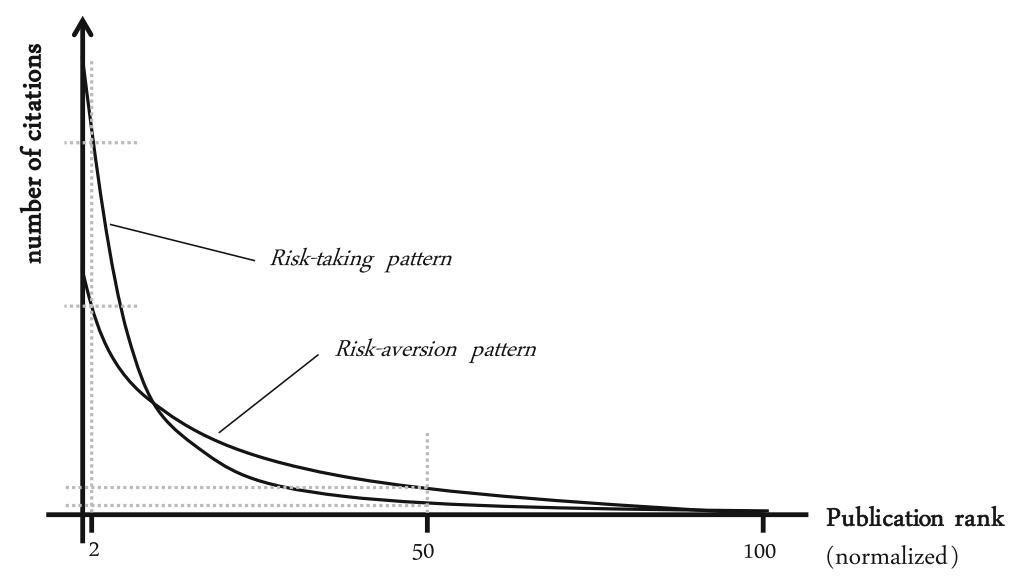

Fig. 1 The schematic curves represent the research output under a regime of high risk-taking and riskaversion, respectively. Calculating the ratio $\left(P_{R}\right)$ between the 98th percentile and the median, the different regimes can be distinguished. To compare the curves visually, the sample sizes were normalized to 100

distinguish patterns which represent the scientific output of projects with high risk levels, and patterns corresponding to only moderate risk levels (see Fig. 1). To compare different risk-return patterns directly, we introduce a new risk parameter $P_{R} . P_{R}$ is sensible to the ratio between high impact research output and average impact output. The parameter is intended for being higher the larger risk-taking. $\mathrm{P}_{\mathrm{R}}$ is defined as the 98 th percentile divided by the median, or:

$$
P_{R}=\frac{Q_{.98}}{Q_{.50}}
$$

within a sample, $\mathrm{P}_{\mathrm{R}}$ therefore indicates how much more often high impact work is cited in comparison to average impact work. As a relative measure, it is independent of the absolute level of citations and is not very sensitive to any particular research area. However, the publication and citation characteristics that differ from one scientific discipline to another might affect $P_{R}$.

$P_{R}$ characterizes the shape of the curves, showing the number of citations versus the paper number, with papers numbered in order of decreasing citations. The parameter's independence of the absolute number of publications and citations makes it also independent of the overall impact or successfulness of the analyzed work. For our sample sizes (between 152 and 2,790 papers), the 98th percentile was found to be more robust against extreme values than, for example, the 99.9th percentile, but still well able to capture the upper most part of the curve. It is, therefore, suited for representing high impact research. The median represents the lower part of the curve or the average research outcome. The citation numbers corresponding to median and 98th percentile, respectively, were calculated by linear interpolation between the closest ranks.

\section{Validation of criterion $\mathbf{P}_{\mathbf{R}}$}

In order to demonstrate the usefulness and the predictive power of the risk parameter $P_{R}$, we analyzed $\mathrm{P}_{\mathrm{R}}$ for several different funding environments. With two different datasets we 
studied the impact of third-party funding and core funding on $\mathrm{P}_{\mathrm{R}}$, once at the micro and once at the meso level. In addition, we examined the difference between individual and project funding, and temporal versus tenured faculty positions.

Data sources

Citation characteristics differ depending on the scientific field. To test the above presented model we had to restrict ourselves to one discipline, and settled on the field of chemistry for three reasons. First, in chemistry, journals are the main source of publication, ensuring a fair amount of publications even on less aggregated levels. Second, co-authorship is less pronounced than in other fields (Melin and Persson 1996), reducing the tendency to assume that each author significantly contributes to a publications' impact. Third, in chemistry, a high correlation between the number of citations as a measure of impact and quality, based on assessments by peers, was found for published papers (Van Raan 2006; Abramo et al. 2009). In order to avoid further biases owing to differing citation densities, we restricted the data acquisition to publications written in English, and as journal articles. In the field of chemistry, the well-established Web of Science is well suited to gather citation numbers (Neuhaus and Daniel 2008). To include more recent papers, we chose variable citation windows $^{3}$ (Moed 1996), and extracted the citation data in July 2011.

\section{Hypotheses and testing}

The following hypotheses are based on the assumption that in otherwise equal environments, faculties' risk-taking depends on their scientific freedom. The lesser faculties have to please peer groups' expectations, the riskier their research ventures are, and the higher the identified $\mathrm{P}_{\mathrm{R}}$.

\section{Limited versus tenured positions}

Professors' faculty positions can be differentiated between permanent and non-permanent appointments. In a Swiss context, the permanent professors (assistant, associate or full professors) are appointed until retirement, and receive stable and comparably high recurrent core funding. The non-permanent professors, mostly assistant professors (tenure track, non-tenure track), are independent in setting their own research agenda, and also receive substantial core funding. However, 4-6 years after having been appointed, their output is evaluated by peer review. This assessment is decisive for future employment and is often perceived as "publish or perish". It is understandable that non-permanent professors may not wish to start risky research endeavors to avoid their efforts having a high probability of no publishable results. On the contrary, they are highly motivated to pass the peer reviewed publication processes and may aim for rather mainstream and low-risk work. This led to the first hypothesis:

(H1): $\quad P_{R}$ is higher for professors with permanent faculty positions compared to nonpermanently employed professors.

\footnotetext{
3 A variable citation window further allows for straightforward data retrieval from electronic databases. Compared to a fixed citation window (Moed 1996), it is, however, prone to underestimating the significance of the differences in $P_{R}$ because even high impact publications need time to receive citations. The period of time between extracting the citation data and the issue date of the latest publications should therefore be in the range of a journal's cited half-life.
} 
To test H1, we looked into the professorate in chemistry at Swiss universities. The eight Swiss universities which have a chemistry department employ 112 full time professors. ${ }^{4} 32$ were non-permanently employed. From those 32 we had to exclude 14 because they started their new positions after 2009, or hadn't yet published anything in a chemistry journal. (They chose publication vehicles from, e.g., cell biology or medical sciences instead). Like Pao (1991), before comparison we extracted a subset of professors from the group of permanent professors. The 11 professors of this latter subset had the highest similarity with the remaining 18 non-permanently employed professors, with respect to their starting year and quantitative publication output. For all remaining professors, we searched in a topdown approach (van Leeuwen 2007) for articles which were published no later than 2003 or the respective professors' starting year in their current position. We searched in the Web of Science for names, then manually checked and cleaned the derived data using information on addresses and institution names. For the permanent professors, we ended up with 160 articles, with an average of 26.9 citations. For the non-permanent professors, we gathered 152 publications with an average of 25.2 citations.

\section{Ratio of third-party and recurrent core funding}

For several years, scholars have speculated that the allocation of research funds by peer judgment would discourage ground-breaking research, and that the focus on third-party funding would foster low-risk and mainstream-oriented research. As a countermeasure, large shares of recurrent core funding is recommended (Laudel 2006b). To test the impact of the share of third-party funding on the university landscape at a meso and micro level, we stated the following two hypotheses:

(H2): Within one institution, $P_{R}$ is higher for professors the lower their percentage of third-party funding.

(H3): For universities, $P_{R}$ is higher the lower the percentage of third-party funding.

We tested H2 with data from the department of chemistry of ETH Zurich. At ETH, the amount of core funding that a chair receives is a matter of negotiation at their appointment or promotion. Third-party funds are raised by the chair on their own. We used the official, non-public financial report of the department to find the funding sources for each professor for the period 2006-2009. We included 5 professors from the field of inorganic chemistry, 7 from organic chemistry and 8 from physical chemistry. We excluded the discipline chemical engineering, assuming different publication characteristics in that field. We further divided the 20 professors into 3 groups, according to the percentage of third-party funding they received: one group with above average; one with below average; and one with an average share of third-party funding. One category is for professors with less than $55 \%$, one for 55-65\%; and one for more than $65 \%$ third-party funding. The thresholds were chosen where we found significant gaps in the distribution, at the same time ensuring that all three groups were of similar size. In a bottom-up approach, similar to van Leeuwen (2007), we extracted the publication lists for the 20 professors from the official annual report, and matched them with the Web of Science to gather the citation counts. We found 756 articles for the years 2006-2009 with an average of 17.9 citations per article.

\footnotetext{
4 These were the universities of: Basel, Berne, Fribourg, Geneva, Neuchâtel, Zürich, EPF Lausanne, and ETH Zurich.
} 
To test H3, we selected 20 renowned universities ${ }^{5}$ using the $\mathrm{ARWU}^{6}$ and the $\mathrm{THE}^{7}$ rankings. To achieve a higher diversity, we did not select strictly, according to the ranking order, but instead underweighted US universities in favor of Asian and continental European universities. To analyze the income streams of the universities, we gathered information from the annual reports or financial statements for the fiscal year 2009, which were published on the universities' own web pages. The six US universities were an exception, where we consulted the official statistical report of the US National Science Foundation on research expenditure for the year 2009 (NSF 2011). We divided the income sources for all universities into two categories: basic, undirected funding, and third-party funding. The first category included state subsidies, block grants, investment income, fees, and endowments. The latter category included research grants, directed donations, and income from contract research. Subsequently, we grouped the universities into institutions with less than 35, 35-85\%, and those with more than $85 \%$ third-party funding. For all 20 universities in the sample, we gathered the publication data from 2003 to 2009 in a topdown approach. We searched in the Web of Science for our chosen universities, using the look-up fields for the organization name and address. We refined the search to the chemical subfields physical chemistry and organic chemistry, since these were the only disciplines that all 20 universities were active in. We found 421-2,790 publications per university, with an average of 18.2 citations per article.

\section{Project versus ad personam funding}

In their study, Heinze et al. (2009) claim that research breakthroughs are strongly enhanced by flexible funding; flexible in the sense of not binding money to any specific purpose, but allowing researchers to use it for "high-risk/high potential investments". They conclude, similar to Bovier et al. (2001), that faculties should have the possibility to reallocate funds towards the most promising ventures. Funding agencies usually allocate funds either directly to individual principal investigators with little restriction, or they fund the execution of a clearly pre-defined project. To test the impact of principal investigators' flexibility in the reallocation of funds, we looked more closely into ad personam funding and project funding schemes and formulated the following hypothesis:

(H4): Funded by the same agency, $P_{R}$ is higher for principal investigators with ad personam grants than for those with project grants.

To test the H4, we extracted the data for all grants approved by the Swiss National Science Foundation in the field of chemistry, for the years 2003-2009. We excluded grants smaller than CHF 20,000, assuming too little impact on recipients' publication records. ${ }^{8}$ We found 463 entries for individual funding and 950 entries for project funding. We searched for publications by the grantees in the Web of Science. Following Defazio et al.

\footnotetext{
5 These were: California Institute of Technology, EPF Lausanne, ETH Zurich, Harvard University, Imperial College London, Kyoto University, Massachusetts Institute of Technology, Nagoya University, National University of Singapore, Seoul National University, Stanford University, Tohoku University, Tokyo Institute of Technology, Trinity College Dublin, TU Munich, University of California Berkeley, University of Oxford, University of Stockholm, Utrecht University, and Yale University.

6 Academic Ranking of World Universities (Shanghai ranking); www.arwu.org.

7 Times Higher Education World University Rankings; www.timeshighereducation.co.uk/world-universityrankings.

8 The highest grant in the resulting sample was CHF $1.6 \mathrm{~m}$, with an average grant size of CHF 281,500.
} 


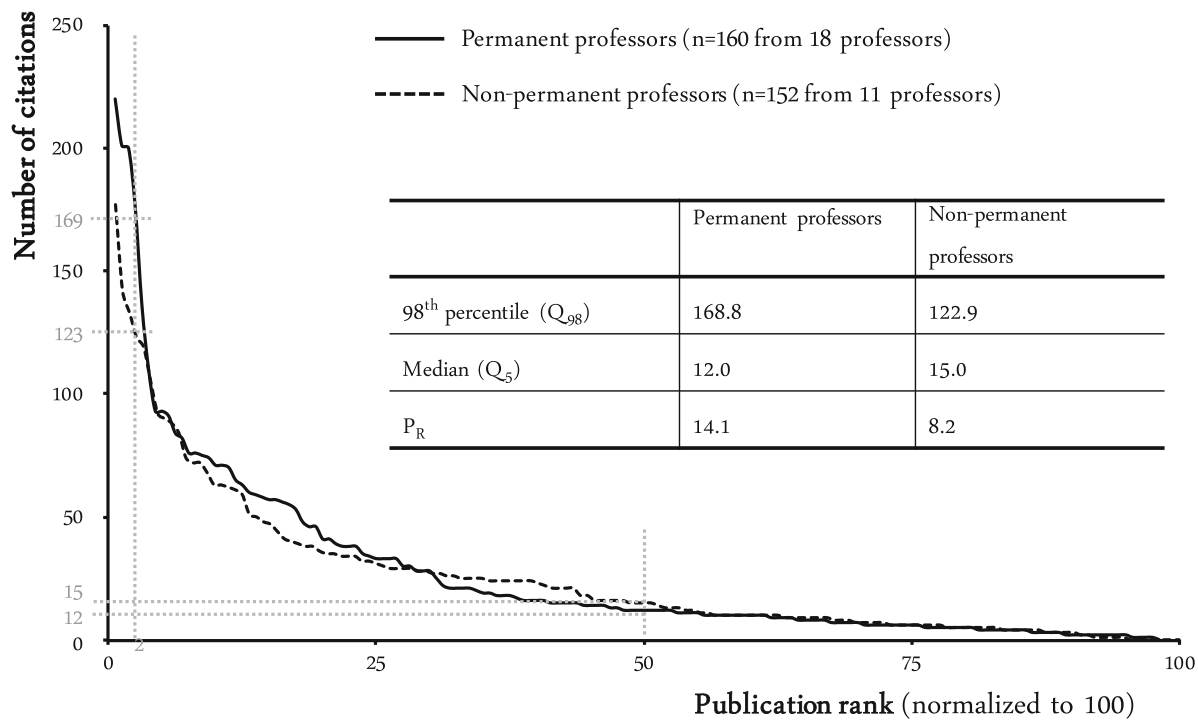

Fig. 2 The rank curves for citations can be distinguished clearly and assigned to more risk-averse research behavior (non-permanent professors), and higher risk-taking behavior (permanent professors), respectively

(2009), we looked for papers published in a window during the period of funding plus the subsequent 2 years. ${ }^{9}$ After manually filtering the Web search by comparing first names, address and institution information, we had 1,411 hits for project funding from 234 different authors and 408 hits for individual funding from 151 different authors. The papers in the group of individual funding were, on average, cited 17.1 times, and the ones in the project funding group 18.1 times.

\section{Results and discussion}

The rationale behind the first hypothesis is that, in a Swiss context, permanent faculty members have a higher incentive to start risky research ventures than non-permanently employed faculty members. In the case of failure, the first group merely has to fear career obstacles or financial setbacks. We did find that the calculated $P_{R}$ for permanent faculties is 14.1, versus 8.2 for non-permanent faculties (see Fig. 2). Hence, H1 can be accepted. Given the condition of solid and concurrent core funding, research managers can influence professors' risk-taking by clarifying their prospects for development.

The analysis of the citation data for different percentages of third-party funded research budgets showed a characteristic correlation between $P_{R}$ and the funding regime. However, the interdependencies contradicted hypotheses $\mathrm{H} 2$ and $\mathrm{H} 3$. As hypothesized, the lowest percentage of third-party funding led to the highest $P_{R}$ values. However, we found that the research groups with the highest percentage of third-party funding had higher $\mathrm{P}_{\mathrm{R}}$ values than the groups with an average level (see Fig. 3). The effects are more pronounced for the micro $(\mathrm{H} 2)$ than for meso $(\mathrm{H} 3)$ level of analysis. This finding is in line with a review by Daniel, who claims that the differences in research output between universities are smaller

\footnotetext{
9 The average grant duration was 24.9 months.
} 


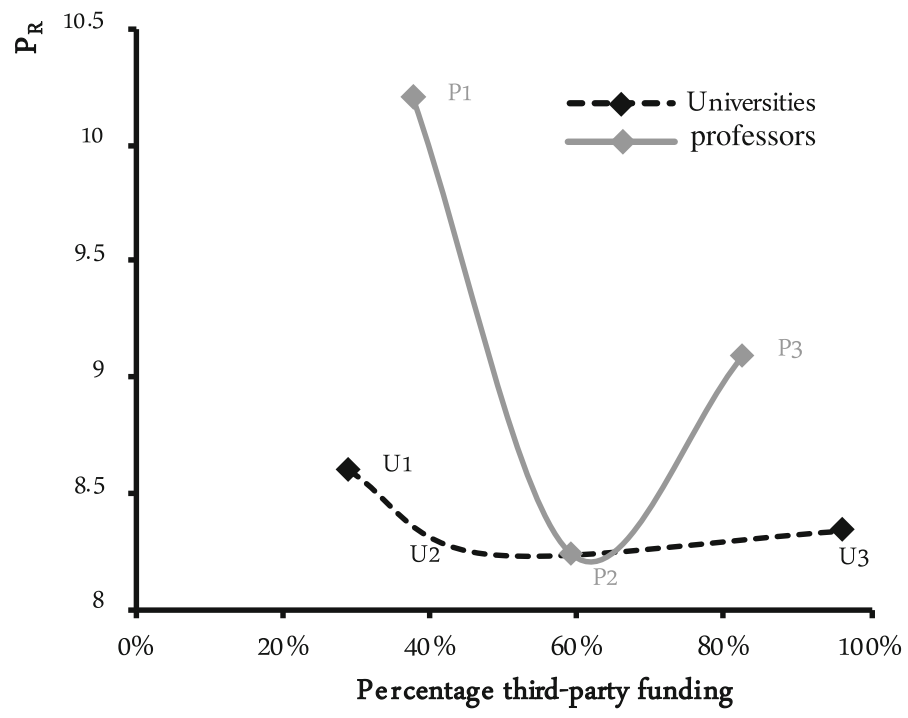

Fig. 3 The relation of third-party funding and $P_{R}$ is $U$-shaped. Faculties with an above average percentage of third-party funding manage to finance their high-risk projects better than those with an average share. However, those with a below average share of third-party funding perform the riskiest research

Table 1 Risk parameter $\mathrm{P}_{\mathrm{R}}$ for professors of physical, inorganic, and organic chemistry at ETH Zurich

\begin{tabular}{lllrr}
\hline Group & \multicolumn{2}{l}{ Third-party funding } & Group size & $\mathrm{P}_{\mathrm{R}}$ \\
\cline { 2 - 4 } & Range (\%) & Average $(\%)$ & \\
\hline P1 & $<55$ & 37.7 & 8 & 10.19 \\
P2 & $55-65$ & 59.4 & 7 & 8.23 \\
P3 & $>65$ & 82.6 & 5 & 9.10 \\
\hline
\end{tabular}

Funding and publications were analyzed for the years 2006-2009

than the differences within a university (Daniel 2001, p. 30). The financial data we acquired are aggregated at an institutional level, and not at the level of the chemistry departments which produced the cited research output. We therefore have to assume a dilution effect for the universities; the meso level (H3).

There are different possible explanations for the U-shaped outcome of the $P_{R}$ versus third-party funding curves. The well-known Matthew effect in science (Merton 1968) might make it easier for already well-financed principal investigators to find funding agencies who accept their risky projects. They might also choose agencies that are more likely to accept shirking ${ }^{10}$ (Van der Meulen 1998), i.e. to retain (Liefner 2003) or divert (Shove 2003) a certain part of the received funds. Or the faculties in groups U3 and P3 (see Tables 1 and 2) might simply have more possibilities to shirk. Since there is a trend to shift the financing streams away from recurrent core funding in many educational systems,

\footnotetext{
${ }^{10}$ In principal-agent relationships, the agent's cheating by exploiting an information asymmetry is often denoted as 'shirking'. The principal does not know for sure if the agent is really doing his or her best after the delegation of a task (Braun and Guston 2003).
} 
Table 2 Risk parameter $P_{R}$ for publications from 2003 to 2009 in the fields of physical and organic chemistry, at different highly ranked universities (for detailed results for each university, see supplement)

\begin{tabular}{|c|c|c|c|c|}
\hline \multicolumn{2}{|c|}{ Group } & \multicolumn{2}{|c|}{$\begin{array}{l}\text { Third-party } \\
\text { funding }\end{array}$} & \multirow[t]{2}{*}{$P_{R}$} \\
\hline & & $\begin{array}{l}\text { Range } \\
(\%)\end{array}$ & $\begin{array}{l}\text { Average } \\
(\%)\end{array}$ & \\
\hline U1 & $\begin{array}{l}\text { EPF Lausanne, ETH Zurich, Nagoya University, National University of } \\
\text { Singapore, Tokyo Institute of Technology, TU Munich, Trinity } \\
\text { College, University of Stockholm }\end{array}$ & $<35$ & 28.9 & 8.60 \\
\hline $\mathrm{U} 2$ & $\begin{array}{l}\text { Imperial College London, Kyoto University, Seoul National University, } \\
\text { Tohoku University, Utrecht University, University of California } \\
\text { Berkeley, University of Oxford }\end{array}$ & $35-85$ & 47.4 & 8.24 \\
\hline U3 & $\begin{array}{l}\text { California Institute of Technology, Harvard University, Massachusetts } \\
\text { Institute of Technology, Stanford University, Yale University }\end{array}$ & $>85$ & 96.5 & 8.34 \\
\hline
\end{tabular}

Funding was analyzed at the level of universities for the year 2009

faculties have to adapt. Presumably, the faculties in groups U3 and P3 were more experienced in grant acquisition, and therefore more successful than those in U2 or P2 in raising funds that allow them to strictly follow their own research agenda (Liefner 2003). The universities are not grouped homogenously in terms of geographical location. An additional explanation for the results of U3 may, therefore, come from its composition. It consists only of private US institutions that may have a different research culture and risktaking attitude from European or East Asian universities.

With the fourth hypothesis we wanted to test whether the Swiss National Science Foundation's individual funding offers more freedom of research than their project funding. This would lead to principal investigators taking more risks. Our results neither support nor reject $\mathrm{H} 4 . \mathrm{P}_{\mathrm{R}}$ is indeed higher for individual funding. However, the difference is weak, and the rank abundance plots of the two different funding regimes are almost identical (see Fig. 4). After interviews with three members of the research council, responsible for granting both individual and project funding in chemistry, we found that, in both cases, the decision-making criteria were similar. They always base their decision on an applicant's track record, as well as on future projects. The importance of a clear research agenda, also in the case of individual funding, might therefore contribute strongly to the indifferent outcome. A noticeable difference between the two funding streams is the composition of career levels of the sponsored principal investigators. While only $8 \%$ of the grants for individual funding were allocated to applicants holding the title of a professor, the value of project funding was $69 \%$. The observed outcome could, therefore, be influenced by the early career stage of the ad personam funded researchers. As discussed in $\mathrm{H} 1$, an early career stage may be prone to risk-aversion and may compensate for a pull on $\mathrm{P}_{\mathrm{R}}$ by individual funding.

\section{Conclusion}

We intended, with this paper, to introduce a quantitative tool that is convenient and easy to apply. The tool should be helpful for evaluating the impact of different funding environments on researchers' risk appetite, and published research output. The tool indeed proved itself to be useful for stimulating the discussion of the four hypotheses, relevant to the 


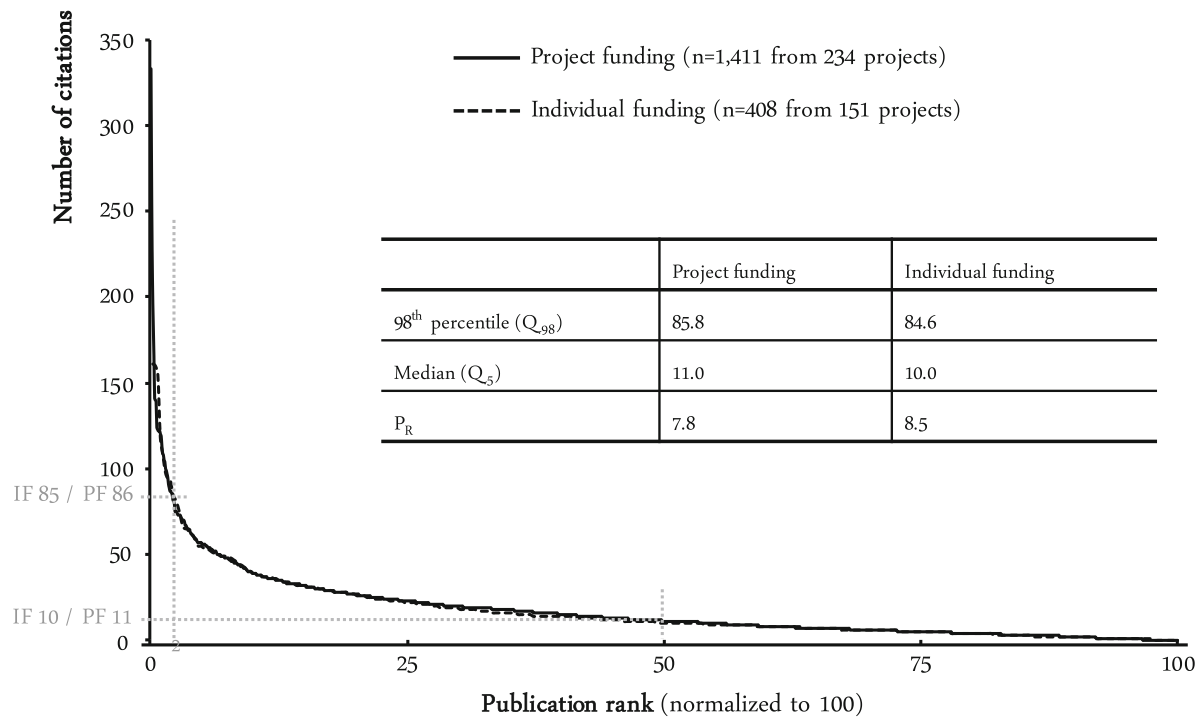

Fig. 4 The rank abundance curve of project funding $(\mathrm{PF})$ is almost congruent with the one for individual funding (IF)

efficacy of the allocation of research funds. For example, members of the research council of the Swiss National Science Foundation were initially surprised to see that their ad personam and project funding led to similar results, until they realized, that in both cases, the allocation criteria were very similar. Our tool should be helpful for many funding agencies and research managers to review their funding instruments' impact, also outside the field of chemistry. The calculation of $P_{R}$ can be a valuable indicator in an academic environment, in mitigating the managerial challenge of finding the right balance between strongly influencing faculties' research agendas and a complete laissez-faire.

In order to directly validate the accuracy of the assumed causality between a researcher's risk-taking behavior and $\mathrm{P}_{\mathrm{R}}$, further longitudinal studies are necessary. Researchers' risk-aversion could thereby be assessed by surveys and the results could later be related to the citation statistics of the published research results. The hypotheses we tested in this paper, to demonstrate the usefulness of $\mathrm{P}_{\mathrm{R}}$, do have their methodological limitations. It was only in the case of $\mathrm{H} 2$ that we were able to use authorized publication lists. In the other cases, we used a top-down approach to search for publications directly on the Web of Science. The publications could, in addition, not be assigned to specific grants. The examined papers do not disclose their funding sources completely, and when they do, they do not comply with any standardized rules. However, self-declaration by the authors also wouldn't be a complete remedy since they are prone to incorrect declarations for political reasons. Another limitation is that the financial statements used for the validation of $\mathrm{H} 3$ were not generated according to the same accounting standards, which limits their comparability. Nevertheless, the different potential sources of error should not lead to any systematic bias, other than diminishing the difference between the two samples that were compared with each other at a time, in all four tests of hypotheses. In general, for a sound comparison of $\mathrm{P}_{\mathrm{R}}$, the different samples have to comprise reasonably large data sets. The results may otherwise be skewed by noise or dissimilar publication characteristics, for example a reluctance to publish, which are not necessarily related to risk-aversion in 
research. The validation of $\mathrm{H} 2$ and $\mathrm{H} 3$ has shown that the Matthew effect and the acceptance of shirking may affect the scientific freedom and therefore influence $P_{R}$. The freedom increases with a principal investigator's standing. A comparison of $P_{R}$, as e.g. the validation of $\mathrm{H} 1$, should therefore consider the equality of the subsets regarding the researchers' career stages.

Despite the weaknesses in some data sets, this paper can also contribute to the ongoing discussion on the impact of peer review and third-party funding on research output. Our results support the findings by Heinze et al., who conducted a qualitative study, and found that core funding without the involvement of any reviewing research council, was very important for achieving breakthrough results in at least two out of five cases (Heinze et al. 2009, p. 618). We showed evidence that high impact research is indeed fostered-at the expense of a lower quantity of medium impact publications - by high recurrent and stable core funding streams. We share the concerns of Heinze et al. (2009) that peer reviewed funding may judge new ideas as too speculative or unorthodox. Peer-review is prone to supporting more conventional mainstream research, with a negative effect on visionary and high-risk approaches.

\section{References}

Abramo, G., D’Angelo, C. A., \& Caprasecca, A. (2009). Allocative efficiency in public research funding: Can bibliometrics help? Research Policy, 38(1), 206-215.

Auranen, O., \& Nieminen, M. (2010). University research funding and publication performance: An international comparison. Research Policy, 39(6), 822-834.

Bolli, T., \& Somogyi, F. (2011). Do competitively acquired funds induce universities to increase productivity? Research Policy, 40(1), 136-147.

Bonaccorsi, A., \& Daraio, C. (2003). Age effects in scientific productivity. Scientometrics, 58(1), 49-90.

Bovier, P. A., Guillain, H., \& Perneger, T. V. (2001). Productivity of medical research in Switzerland. Journal of Investigative Medicine, 49(1), 77-84.

Braun, D., \& Guston, D. H. (2003). Principal-agent theory and research policy: An introduction. Science and Public Policy, 30(5), 302-308.

Butler, L. (2003). Explaining Australia's increased share of ISI publications-the effects of a funding formula based on publication counts. Research Policy, 32(1), 143-155.

Carayol, N., \& Matt, M. (2004). Does research organization influence academic production? Laboratory level evidence from a large European university. Research Policy, 33(8), 1081-1102.

Carayol, N., \& Matt, M. (2006). Individual and collective determinants of academic scientists' productivity. Information Economics and Policy, 18(1), 55-72.

Daniel, H. D. (2001). Wissenschaftsevaluation: Neuere Entwicklungen und heutiger Stand der Forschungsund Hochschulevaluation in ausgewählten Ländern. Bern: Center for Science and Technology Studies.

Defazio, D., Lockett, A., \& Wright, M. (2009). Funding incentives, collaborative dynamics and scientific productivity: Evidence from the EU framework program. Research Policy, 38(2), 293-305.

Dundar, H., \& Lewis, D. R. (1998). Determinants of research productivity in higher education. Research in Higher Education, 39(6), 607-631.

Geuna, A. (2001). The changing rationale for European university research funding: Are there negative unintended consequences? Journal of Economic Issues, 35(3), 607-632.

Goldfarb, B. (2008). The effect of government contracting on academic research: Does the source of funding affect scientific output? Research Policy, 37(1), 41-58.

Heinze, T. (2008). How to sponsor ground-breaking research: A comparison of funding schemes. Science and Public Policy, 35(5), 302-318.

Heinze, T., Shapira, P., Rogers, J. D., \& Senker, J. M. (2009). Organizational and institutional influences on creativity in scientific research. Research Policy, 38(4), 610-623.

Henkel, M. (2000). Academic identities and policy change in higher education (Vol. 46). London: Jessica Kingsley Publishers.

Hirsch, J. E. (2005). An index to quantify an individual's scientific research output. Proceedings of the National Academy of Sciences of the United States of America, 102(46), 16569. 
Hornbostel, S. (2001). Third party funding of German universities. An indicator of research activity? Scientometrics, 50(3), 523-537.

Kuhn, T. S. (1962). The structure of scientific revolutions. Chicago: University of Chicago Press.

Laudel, G. (2006a). The art of getting funded: How scientists adapt to their funding conditions. Science and Public Policy, 33(7), 489-504.

Laudel, G. (2006b). The 'quality myth': Promoting and hindering conditions for acquiring research funds. Higher Education, 52(3), 375-403.

Leitner, K. H., Prikoszovits, J., Schaffhauser-Linzatti, M., Stowasser, R., \& Wagner, K. (2007). The impact of size and specialisation on universities' department performance: A DEA analysis applied to Austrian universities. Higher Education, 53(4), 517-538.

Lepori, B., van den Besselaar, P., Dinges, M., Potì, B., Reale, E., Slipersæter, S., et al. (2007). Comparing the evolution of national research policies: What patterns of change? Science and Public Policy, 34(6), 372-388.

Lewison, G., \& Dawson, G. (1998). The effect of funding on the outputs of biomedical research. Scientometrics, 41(1), 17-27.

Leydesdorff, L., \& Wagner, C. (2009a). Is the United States losing ground in science? A global perspective on the world science system. Scientometrics, 78(1), 23-36.

Leydesdorff, L., \& Wagner, C. (2009b). Macro-level indicators of the relations between research funding and research output. Journal of Informetrics, 3(4), 353-362.

Liefner, I. (2003). Funding, resource allocation, and performance in higher education systems. Higher Education, 46(4), 469-489.

Marginson, S., \& Considine, M. (2000). The enterprise university: Power, governance, and reinvention in Australia. Cambridge: Cambridge University Press.

Melin, G., \& Persson, O. (1996). Studying research collaboration using co-authorships. Scientometrics, 36(3), 363-377.

Merton, R. K. (1968). The Matthew effect in science. Science, 159(3810), 56.

Moed, H. (1996). Differences in the construction of SCI based bibliometric indicators among various producers: A first overview. Scientometrics, 35(2), 177-191.

Musselin, C. (2005). European academic labor markets in transition. Higher Education, 49(1), $135-154$.

National Science Foundation, National Center for Science and Engineering Statistics. (2011). Academic Research and Development Expenditures: Fiscal Year 2009. (vol. 2011).

Neuhaus, C., \& Daniel, H. D. (2008). Data sources for performing citation analysis: An overview. Journal of Documentation, 64(2), 193-210.

Pao, M. L. (1991). On the relationship of funding and research publications. Scientometrics, 20(1), $257-281$.

Shove, E. (2003). Principals, agents and research programmes. Science and Public Policy, 30(5), 371-381.

Tammi, T. (2009). The competitive funding of university research: The case of Finnish science universities. Higher Education, 57(5), 657-679.

Tatsioni, A., Vavva, E., \& Ioannidis, J. P. A. (2010). Sources of funding for Nobel Prize-winning work: Public or private? The FASEB Journal, 24(5), 1335-1339.

Van der Meulen, B. (1998). Science policies as principal-agent games: Institutionalization and path dependency in the relation between government and science. Research Policy, 27(4), 397-414.

van Leeuwen, T. N. (2007). Modelling of bibliometric approaches and importance of output verification in research performance assessment. Research Evaluation, 16(2), 93-105.

Van Raan, A. F. J. (2006). Comparison of the Hirsch-index with standard bibliometric indicators and with peer judgment for 147 chemistry research groups. Scientometrics, 67(3), 491-502.

Weber, L., \& Duderstadt, J. J. (2004). Reinventing the research university. London: Economica.

Weingart, P. (2005). Impact of bibliometrics upon the science system: Inadvertent consequences? Scientometrics, 62(1), 117-131.

Whitley, R. (2003). Competition and pluralism in the public sciences: The impact of institutional frameworks on the organisation of academic science. Research Policy, 32(6), 1015-1029.

Zhao, D. (2010). Characteristics and impact of grant-funded research: A case study of the library and information science field. Scientometrics, 84(2), 293-306. 